\title{
Prevalence of and Risk Factors for Prostatitis in African American Men:The Flint Mens Health Study
}

\author{
Lauren P. Wallner, ${ }^{1,2 *}$ J. Quentin Clemens, ${ }^{1}$ and Aruna V. Sarma ${ }^{1,2}$ \\ 'Department of Urology, University of Michigan, Ann Arbor, Michigan \\ ${ }^{2}$ Department of Epidemiology, University of Michigan, Ann Arbor, Michigan
}

\begin{abstract}
INTRODUCTION. Prostatitis is a common, yet ill-defined condition without clear diagnostic criteria and treatment strategies. Previous studies examining the prevalence and correlates of prostatitis are limited in their inclusion of primarily white populations. The objective of the current study was to identify prevalence of and risk factors for prostatitis in a population-based sample of African-American men.

METHODS. In 1996, a probability sample of 703 African-American men, aged 40-79, residing in Genesee County, Michigan without a prior history of prostate cancer/surgery provided responses to a structured interview-administered questionnaire which elicited information regarding sociodemographics, current stress and health ratings, and past medical history, including history of physician diagnosed prostatitis, BPH and sexually transmitted diseases. Logistic regression was used to identify predictors of prostatitis after adjustment for age.

RESULTS. Forty-seven $(6.7 \%)$ of the 703 men reported a history of prostatitis. Increased frequency of sexual activity and physical activity were significantly associated with decreased odds of disease. Moderate to severe lower urinary tract symptoms (LUTS) and a history of BPH were significantly associated with prostatitis after adjustment for age.

CONCLUSION. After adjustment for age, LUTS severity and history of BPH were associated with increased odds of prostatitis. BMI, physical activity and sexual frequency were associated with decreased odds of prostatitis. Finally, poor emotional and physical health, high perceived stress and low social support were associated with an increased risk of prostatitis history. Importantly, these findings suggest that the primary risk factors for this condition are largely modifiable and highlight potential targets for future prevention. Prostate 69: 24-32, 2009. (C) 2008 Wiley-Liss, Inc.
\end{abstract}

KEY WORDS: African-American; prostatitis; sexually transmitted diseases

\section{BACKGROUND}

Prostatitis is a common, yet ill-defined condition without clear diagnostic criteria and treatment strategies [1]. To limit confusion regarding case identification, a prostatitis classification system was developed by the National Institutes of Health which includes four categories: (I) acute bacterial prostatitis, (II) chronic bacterial prostatitis, (III) chronic prostatitis/chronic pelvic pain syndrome, and (IV) asymptomatic inflammatory prostatitis [2]. Five to $10 \%$ of prostatitis cases are known to be bacterial but etiology is unknown in more than $90 \%$ of cases which are usually classified as type III.

It has been estimated that a diagnosis of prostatitis accounts for 2 million physician office visits annually in the United States, including $8 \%$ of urology and $1 \%$ of primary care visits [3]. In a review of six studies of prostatitis, $8.7 \%$ of men overall met various criteria for symptoms of the disease with prevalence estimates ranging from $2.2 \%$ to $9.7 \%$ [4]. Several populationbased studies have identified age, race, and geographic region as significant risk factors for chronic prostatitis [5-7]. Urologic characteristics such as lower urinary tract symptoms, history of benign prostatic hyperplasia

*Correspondence to: Lauren P. Wallner, MPH, Department of Urology, University of Michigan Health System, 1500 E. Medical Center Drive, Ann Arbor, MI 48109-0759.

E-mail: lwallner@umich.edu

Received 17 June 2008; Accepted 29 July 2008

DOI 10.1002/pros.20846

Published online 18 September 2008 in Wiley InterScience (www.interscience.wiley.com). 
(BPH) or urinary tract infection and decreased ejaculation frequency have also been demonstrated to increase risk $[5,8]$. Studies focusing on sociodemographic factors including education, income and profession have yielded inconsistent results $[9,10]$.

With the increasing interest in the role of infection and chronic inflammation in the development of prostate cancer, several studies have examined the relationships between sexual behavior, sexually transmitted diseases (STDs), prostatitis and prostate cancer risk [11-13]. While these studies suggest that prior infections of the prostate are associated with prostate cancer, they are limited in their inclusion of primarily clinically referred samples and white populations.

The objective of the current study was to determine the prevalence of and risk factors for self-reported physician-diagnosed prostatitis in the Flint Men's Health Study, a population based sample of community dwelling African-American men aged 40-79 years.

\section{MATERIALS AND METHODS}

\section{Study Subjects}

In 1996, a probability sample of 943 African-American men was selected from households located in Genesee County, MI to participate in a study on risk factors for prostate cancer. Among the 817 men who agreed to participate ( $87 \%$ response rate), 730 subjects without a history of prostate cancer/surgery were administered a detailed in home epidemiologic interview ascertaining information on general health and medical history, sexual activity and history of STDs, health care use and socio-demographic information $[12,14]$.

At the conclusion of the interview 379 of the 730 subjects underwent a comprehensive urologic examination (uroflowmetry, digital rectal exam (DRE), transrectal ultrasound (TRUS), serum PSA measurement), anthropometric measurements and completion of the American Urological Association Symptom Index (AUASI). Prostate biopsy was recommended in individuals with an elevated PSA $(4.0 \mathrm{ng} / \mathrm{ml}$ or greater) or suspicious DRE. Eleven men at baseline who were found to have positive biopsies for prostate cancer and an additional 16 men who developed prostate cancer during the study period were excluded. The final sample of 703 men from the interview-phase and 369 men from the clinic-phase were included in this analysis. The study was approved by the University of Michigan Institutional Review Board.

\section{Measurements}

In-person interviews gathered information regarding various health, behavioral, and socio-demographic characteristics from all participants. Subjects were queried about age at first sexual intercourse, lifetime number of sexual partners and frequency of sexual activity in the past year. Subjects were asked to report history and frequency of physician diagnosed: gonorrhea, syphilis, herpes or other venereal disease. Information regarding history of human papilloma virus (HPV) was ascertained by asking subjects if any of their partners had cancer of the cervix before or during their acquaintance.

Self-reported weight and height was used to calculate body mass index (BMI) [weight $(\mathrm{kg}) /$ height $\left(\mathrm{m}^{2}\right)$ ]. Physical activity during the past year was assessed by querying participants about their daily physical activity at both work and for recreation. Subjects were also queried about current and former cigarette and alcohol consumption. Socio-demographic data included information on: age, marital status, education level, and income status. Subjects were determined to have a family history of prostate cancer if they reported that a first-degree relative had been diagnosed. Subjects were also asked to report history and date of physician-diagnosed prostatitis and $\mathrm{BPH}$.

Participants also completed the Perceived Stress Scale (PSS), a validated questionnaire designed to measure the degree to which respondents find their lives stressful [15]. Stressful life events were assessed by querying participants about the occurrence of seven of the most stressful life events identified in the literature $[16,17]$. In addition, supportive and negative social interactions with family and friends were assessed. Finally, participants were asked to rate overall physical and emotional health [17]. Individual questions are included in the Appendix.

\section{Statistical Analysis}

Distributions of sociodemographic, sexual history and urinary characteristics were examined by prostatitis status and tested using Pearsons chi-square test for association and Cochran-Armitage test for trend. Logistic regression models estimated age-adjusted odds ratios and $95 \%$ confidence intervals. Two-tailed tests were used for all comparisons and $P$-values of $<0.05$ were considered statistically significant. All analyses were performed using Statistical Analysis System 9.1 (SAS Institute, Inc., Cary, NC).

\section{RESULTS}

In this sample of 703 African American men, $47(6.7 \%)$ overall reported a history of physician-diagnosed prostatitis. These men were significantly older compared to men with no history of prostatitis $(P=0.025)$ (Table I). Other factors including income, 
TABLE I. Sociodemographic, Medical History and Lifestyle Characteristics by Prostatitis Status among African-American Men $(n=703)$

\begin{tabular}{|c|c|c|c|c|}
\hline & $\begin{array}{l}\text { No history } \\
\text { of prostatitis } \\
(n=656)\end{array}$ & $\begin{array}{l}\text { History of } \\
\text { prostatitis } \\
\quad(n=47)\end{array}$ & $\begin{array}{c}P \text {-value } \\
\text { (based } \\
\text { on chi-square) }\end{array}$ & $\begin{array}{l}\text { Age-adjusted } \\
\text { odds ratio } \\
(95 \% \mathrm{CI})\end{array}$ \\
\hline \multicolumn{5}{|l|}{ Sociodemographic characteristics } \\
\hline Age (years), mean (SD) & $57.4(10.78)$ & $61.0(10.23)$ & $0.0250^{\mathrm{a}}$ & - \\
\hline $40-49$ & $186(28.4)$ & $6(12.7)$ & 0.069 & - \\
\hline $50-59$ & $191(29.1)$ & $16(34.4)$ & & \\
\hline $60-69$ & $157(24.0)$ & $11(23.4)$ & & \\
\hline $70-79$ & $122(18.6)$ & $14(29.8)$ & & \\
\hline Income $(\$)$ & & & 0.240 & \\
\hline$<15,000$ & $108(23.7)$ & $9(25.0)$ & & - \\
\hline $15,000-29,999$ & $117(25.7)$ & $15(41.7)$ & & $1.50(0.63,3.57)$ \\
\hline $30,000-49,999$ & 89 (19.5) & $5(13.9)$ & & $0.70(0.23,2.17)$ \\
\hline $50,000-73,999$ & $77(16.9)$ & $3(8.3)$ & & $0.55(0.14,2.18)$ \\
\hline$\geq 74,000$ & $65(14.3)$ & $4(11.1)$ & & $0.84(0.24,2.93)$ \\
\hline Education & & & 1.00 & \\
\hline Less than high school & $263(40.1)$ & $19(40.4)$ & & - \\
\hline High school or greater & $393(59.9)$ & $28(59.6)$ & & $1.33(0.69,2.56)$ \\
\hline Marital status & & & 0.861 & \\
\hline Married/living with partner & $380(58.0)$ & $25(53.2)$ & & - \\
\hline Divorced/separated/widowed & $213(32.6)$ & $19(40.4)$ & & $1.27(0.68,2.37)$ \\
\hline Never married & $62(9.5)$ & $3(6.4)$ & & $0.86(0.25,2.98)$ \\
\hline \multicolumn{5}{|l|}{ Medical history } \\
\hline Family history of prostate cancer & & & 0.929 & \\
\hline No & $520(79.3)$ & $37(78.7)$ & & - \\
\hline Yes & $136(20.7)$ & $10(21.3)$ & & $1.04(0.50,2.15)$ \\
\hline DRE test in last 5 years & & & 0.205 & \\
\hline No & $210(32.3)$ & $11(23.4)$ & & - \\
\hline Yes & $440(67.7)$ & $36(76.6)$ & & $1.34(0.66,2.73)$ \\
\hline PSA test in last 5 years & & & 0.120 & \\
\hline No & $335(55.1)$ & $17(42.5)$ & & - \\
\hline Yes & $274(44.9)$ & $23(57.5)$ & & $1.49(0.76,2.89)$ \\
\hline \multicolumn{5}{|l|}{ Lifestyle characteristics } \\
\hline Body mass index $\left(\mathrm{kg} / \mathrm{m}^{2}\right)$ & & & 0.048 & \\
\hline Normal $(<25)$ & $228(35.2)$ & $22(48.9)$ & & - \\
\hline Overweight (25-29) & $248(38.3)$ & $18(40.0)$ & & $0.76(0.49,1.46)$ \\
\hline Obese $(\geq 30)$ & $171(26.4)$ & $5(11.1)$ & & $0.32(0.12,0.87)$ \\
\hline Alcohol use status & & & 0.460 & \\
\hline Never & $106(16.2)$ & $6(13.3)$ & & - \\
\hline Former & $236(36.0)$ & $15(33.3)$ & & $1.03(0.40,2.73)$ \\
\hline Current & $313(47.8)$ & $24(53.3)$ & & $1.44(0.57,3.64)$ \\
\hline Cigarette smoking status & & & 0.420 & \\
\hline Never & $147(22.4)$ & $9(19.2)$ & & - \\
\hline Former & $245(37.4)$ & $25(53.2)$ & & $1.49(0.67,3.32)$ \\
\hline Current & $264(47.8)$ & $13(27.7)$ & & $0.85(0.35,2.05)$ \\
\hline Physical activity (TEE) & & & 0.002 & \\
\hline Less than $3,274 \mathrm{kcal} /$ day & $154(23.6)$ & $20(42.5)$ & & - \\
\hline $3,274-4,027 \mathrm{kcal} /$ day & $166(25.5)$ & $11(23.4)$ & & $0.53(0.25,1.15)$ \\
\hline $4,027-4,976 \mathrm{kcal} /$ day & $162(24.9)$ & $10(21.3)$ & & $0.53(0.24,1.19)$ \\
\hline$>4,976 \mathrm{kcal} /$ day & 169 (25.9) & $6(12.8)$ & & $0.33(0.13,0.88)$ \\
\hline Physical health rating (mean, SD) & $3.11(1.12)$ & $3.81(1.09)$ & $<0.001^{\mathrm{a}}$ & \\
\hline Excellent/good & $173(26.4)$ & $5(10.6)$ & 0.016 & - \\
\hline Fair/poor & $482(73.6)$ & $42(89.4)$ & & $2.80(1.09,7.22)$ \\
\hline Emotional health rating (mean, SD) & $2.88(1.14)$ & $3.43(1.21)$ & $0.002^{\mathrm{a}}$ & \\
\hline Excellent/good & $225(34.4)$ & $11(23.4)$ & 0.125 & - \\
\hline Fair/poor & $430(65.6)$ & $36(76.6)$ & & $\begin{array}{r}1.68(0.84,3.37) \\
(\text { Continued })\end{array}$ \\
\hline
\end{tabular}




\begin{tabular}{|c|c|c|c|c|}
\hline & $\begin{array}{l}\text { No history } \\
\text { of prostatitis } \\
(n=656)\end{array}$ & $\begin{array}{l}\text { History of } \\
\text { prostatitis } \\
\quad(n=47)\end{array}$ & $\begin{array}{c}P \text {-value } \\
\text { (based } \\
\text { on chi-square) }\end{array}$ & $\begin{array}{l}\text { Age-adjusted } \\
\text { odds ratio } \\
(95 \% \mathrm{CI})\end{array}$ \\
\hline Perceived stress score (mean, SD) & $3.58(3.23)$ & $4.49(3.71)$ & $0.114^{\mathrm{a}}$ & \\
\hline Low stress $(<5)$ & $436(66.6)$ & $23(48.9)$ & 0.014 & - \\
\hline High stress $(\geq 5)$ & $219(33.4)$ & $24(51.1)$ & & $2.27(1.24,4.13)$ \\
\hline Number of stressful life events (mean, SD) & $1.04(1.02)$ & $1.36(1.21)$ & $0.081^{\mathrm{a}}$ & $1.39(1.07,1.82)$ \\
\hline Social support score (mean, SD) & $8.53(2.55)$ & $7.70(2.47)$ & $0.044^{\mathrm{a}}$ & \\
\hline Low support $(<8)$ & $193(29.5)$ & $20(43.4)$ & 0.046 & - \\
\hline High support $(\geq 8)$ & $462(70.5)$ & $26(56.5)$ & & $0.56(0.31,1.04)$ \\
\hline
\end{tabular}

Totals may not equal $\mathrm{n}=703$ due to missing values.

${ }^{a}$ Kruskall-Wallis Test.

education, marital status, family history of prostate cancer, or past DRE or PSA testing were not found to differ by prostatitis status. However, obese men $(\mathrm{BMI} \geq 30)$ and men who reported being very physically active $(>4,976 \mathrm{kcal} /$ day) were $67 \%$ and $70 \%$ less likely, respectively, to have a history of prostatitis after adjustment for age (Table I).

Men reporting poor physical health were 2.8 times more likely to have a history of prostatitis compared to men with excellent/good ratings of physical health after adjustment for age (OR $=2.80,95 \%$ CI 1.09-7.22) (Table I). This increased risk of prostatitis was also observed among men who reported poor emotional health $(P=0.002)$, although this association was attenuated after adjustment for age. High perceived stress was significantly associated with prostatitis $(\mathrm{OR}=2.27$, 95\% CI 1.24-4.13) and the number of stressful life events was significantly higher in men with prostatitis after adjustment for age (OR $=1.39,95 \%$ CI 1.07-1.82). We also observed that men with prostatitis were approximately half as likely to report high social support compared to men without prostatitis $(\mathrm{OR}=0.56,95 \%$ CI: 0.31-1.04) (Table I).

The distribution of sexual history characteristics in the sample is presented in Table II. Specifically, decreased frequency of sexual activity was associated with increased risk of prostatitis, with only $21.1 \%$ of men with prostatitis history reporting sexual activity two or more times a week compared to $43.8 \%$ of men with no history of prostatitis $(P=0.004)$. However, this relationship was no longer statistically significant after adjustment for age $(\mathrm{OR}=0.61,95 \% \mathrm{CI}$ $0.22-1.72$ ). No other sexual history characteristics were found to significantly differ by prostatitis status. Although increased frequency of gonorrhea and herpes infections were found to be slightly more common among men who reported a history of pros- tatitis, these findings were not statistically significant (Table II).

Table III presents the distribution of $\mathrm{BPH}$ measures by prostatitis. A significantly greater number of men with a history of BPH reported prostatitis $(45.7 \%)$. After adjustment for age, this translated to an 11-fold increased risk of prostatitis in men with a history of $\mathrm{BPH}$ compared to men without BPH $(\mathrm{OR}=11.92,95 \% \mathrm{CI}$ 5.99-23.75). Additionally, 64\% of men with prostatitis reported moderate to severe LUTS compared to only $38.4 \%$ of men with no history of prostatitis $(\mathrm{OR}=2.74$, 95\% CI 1.17-6.42). Although men with prostatitis were slightly more likely to have increased prostate volumes and PSA concentrations, these associations were not statistically significant after adjustment for age. No differences in peak urinary flow rates were observed by prostatitis status (Table III).

\section{DISCUSSION}

Among this population-based sample of African American men, 47 (6.7\%) reported a previous history of prostatitis. This prevalence estimate is consistent with previously published data from studies focusing primarily on white populations whose estimates ranged from $2 \%$ to $10 \%$ [5]. Overall, men reporting history of prostatitis in this sample were older. While it has been suggested that prostatitis is a younger man's disease, these findings are consistent with several other reports which demonstrate that prostatitis affects men of all ages. Specifically, Clemens et al. demonstrated that in a managed care population, 1 in 10 men ages $70+$ were diagnosed with prostatitis [18]. Mehik etal. [9] found that prostatitis prevalence in a Finnish population increases with age. However, The Olmsted County Study found no difference in age when comparing men by prostatitis status in those ages 66 years and 
TABLE II. Sexual Behavior and Sexually Transmitted Disease History by Prostatitis Status among African American Men $(\mathbf{n}=\mathbf{7 0 3})$

\begin{tabular}{|c|c|c|c|c|}
\hline & $\begin{array}{c}\text { No history of } \\
\text { prostatitis }(n=656)\end{array}$ & $\begin{array}{c}\text { History of } \\
\text { prostatitis }(n=47)\end{array}$ & $\begin{array}{c}P \text {-value } \\
\text { (based on } \\
\text { chi-square) }\end{array}$ & $\begin{array}{c}\text { Age-adjusted } \\
\text { odds ratio }(95 \% \mathrm{CI})\end{array}$ \\
\hline \multicolumn{5}{|l|}{ Sexual behaviors } \\
\hline \multicolumn{5}{|l|}{ Sexual frequency in past 12 months } \\
\hline None & $84(13.2)$ & $7(15.22)$ & $0.004 / 0.004^{*}$ & - \\
\hline 1-2 times & $63(9.9)$ & $12(26.1)$ & & $2.48(0.92,6.73)$ \\
\hline 1-3 times/month & $75(11.8)$ & $8(17.4)$ & & $1.44(0.49,4.22)$ \\
\hline 1 time/week & 135 (21.3) & $8(17.4)$ & & $0.84(0.29,2.45)$ \\
\hline $2+$ times/week & $278(43.8)$ & $11(23.9)$ & & $0.61(0.22,1.72)$ \\
\hline Number of sexual partners & & & $0.424 / 0.428^{*}$ & \\
\hline $1-5$ & $117(24.7)$ & $8(24.2)$ & & - \\
\hline $6-11$ & $114(24.1)$ & $12(36.7)$ & & $1.51(0.59,3.84)$ \\
\hline $12-24$ & $121(25.6)$ & $6(18.2)$ & & $0.74(0.25,2.21)$ \\
\hline$\geq 25$ & $122(25.7)$ & $7(21.1)$ & & $0.89(0.31,2.53)$ \\
\hline Age at first sexual intercourse & & & $0.882 / 0.487^{*}$ & \\
\hline$<14$ & $147(23.1)$ & $10(22.2)$ & & - \\
\hline $14-15$ & $163(25.6)$ & $9(20.0)$ & & $0.70(0.27,1.78)$ \\
\hline $16-17$ & $105(16.5)$ & $8(17.8)$ & & $1.01(0.38,2.66)$ \\
\hline$>17$ & $221(34.75)$ & $18(40.0)$ & & $1.03(0.48,2.33)$ \\
\hline \multicolumn{5}{|l|}{ STD history } \\
\hline History of STDs & & & 0.123 & \\
\hline Never & $297(45.6)$ & $16(34.1)$ & & - \\
\hline 1 or more & $354(51.4)$ & $31(65.9)$ & & $1.57(0.84,2.94)$ \\
\hline History of gonorrhea & & & 0.213 & \\
\hline No & $310(47.4)$ & $18(38.3)$ & & - \\
\hline Yes & $340(52.3)$ & $29(61.7)$ & & $1.42(0.77,2.62)$ \\
\hline No. of times had gonorrhea & & & $0.141 / 0.070^{*}$ & \\
\hline 0 & $310(48.0)$ & $18(38.3)$ & & - \\
\hline 1 & $184(28.5)$ & $12(25.5)$ & & $1.07(0.51,2.29)$ \\
\hline$>1$ & $152(23.5)$ & $17(36.2)$ & & $1.90(0.95,3.81)$ \\
\hline History of syphilis & & & 0.566 & \\
\hline No & $627(96.2)$ & $45(97.8)$ & & - \\
\hline Yes & $25(3.8)$ & $1(2.2)$ & & $0.49(0.07,3.75)$ \\
\hline No. of times had syphilis & & & $0.885 / 0.626^{*}$ & \\
\hline 0 & $631(96.7)$ & $46(97.9)$ & & - \\
\hline 1 & $21(3.2)$ & $1(2.0)$ & & $0.58(0.08,4.44)$ \\
\hline$>1$ & $1(0.15)$ & $0(0.0)$ & & $\mathrm{n} / \mathrm{a}$ \\
\hline History of herpes & & & 0.596 & \\
\hline No & $645(98.7)$ & $46(97.9)$ & & - \\
\hline Yes & $8(1.3)$ & $1(2.1)$ & & $2.09(0.25,17.3)$ \\
\hline No. of times had herpes & & & $0.043 / 0.090^{*}$ & \\
\hline 0 & $648(99.2)$ & $46(97.8)$ & & - \\
\hline 1 & $4(0.6)$ & $0(0.0)$ & & $\mathrm{n} / \mathrm{a}$ \\
\hline$>1$ & $1(0.2)$ & $1(2.1)$ & & $19.5(1.14,334.93)$ \\
\hline Partner history of cervical cancer & & & 0.369 & \\
\hline No & $600(98.2)$ & $44(100.0)$ & & - \\
\hline Yes & $11(1.8)$ & $0(0.0)$ & & $\mathrm{n} / \mathrm{a}$ \\
\hline
\end{tabular}

* $P$-value based on chi-square test for trend.

older [19]. While age may not causally influence prostatitis risk, it is related to most factors speculated to be associated with the condition.

Several studies have demonstrated a relationship between prostatitis and $\mathrm{BPH}$, suggesting prostatic in- fections promote inflammation resulting in an increase in prostate size. Alternatively, an increase in prostate volume may promote recurrent infections due to incomplete emptying of the bladder. In the Healthcare Professionals without Prostate Cancer study, BPH was 
TABLE III. Benign Prostatic Hyperplasia Measures by Prostatitis Status Among African-American Men $(\mathbf{n}=\mathbf{7 0 3})$

\begin{tabular}{|c|c|c|c|c|}
\hline & $\begin{array}{l}\text { No history } \\
\text { of prostatitis } \\
(n=656)\end{array}$ & $\begin{array}{l}\text { History of } \\
\text { prostatitis } \\
(\mathrm{n}=47)\end{array}$ & $\begin{array}{c}\text { P-value } \\
\text { (based on } \\
\text { chi-square) }\end{array}$ & $\begin{array}{c}\text { Age-adjusted } \\
\text { odds ratio } \\
(95 \% \mathrm{CI})\end{array}$ \\
\hline History of physician diagnosed $\mathrm{BPH}$ & & & $<0.001$ & \\
\hline No & $614(93.7)$ & $25(54.3)$ & & - \\
\hline Yes & $41(6.3)$ & $21(45.7)$ & & $11.93(5.98,23.8)$ \\
\hline AUASI score $^{\mathrm{a}}$ & & & 0.018 & \\
\hline$<7$ mild $/$ moderate & $202(61.5)$ & $9(36.0)$ & & - \\
\hline$\geq 7$ moderate $/$ severe & $126(38.4)$ & $16(64.0)$ & & $2.74(1.17,6.42)$ \\
\hline Prostate volume $\left(\mathrm{cm}^{3}\right)^{\mathrm{a}}$ & & & 0.266 & \\
\hline$<30 \mathrm{~cm}^{3}$ & $210(66.5)$ & $13(54.2)$ & & - \\
\hline$\geq 30 \mathrm{~cm}^{3}$ & $106(33.5)$ & $11(45.8)$ & & $1.46(0.62,3.46)$ \\
\hline Peak flow rate $(\mathrm{ml} / \mathrm{sec})^{\mathrm{a}}$ & & & 0.961 & \\
\hline$\geq 12 \mathrm{ml} / \mathrm{sec}$ & $209(65.7)$ & $15(65.2)$ & & - \\
\hline$<12 \mathrm{ml} / \mathrm{sec}$ & $109(34.3)$ & $8(34.8)$ & & $0.86(0.34,2.19)$ \\
\hline PSA level $(\mathrm{ng} / \mathrm{ml})^{\mathrm{a}}$ & & & 0.230 & \\
\hline$<4 \mathrm{ng} / \mathrm{ml}$ & $634(96.7)$ & $44(93.6)$ & & - \\
\hline$\geq 4 \mathrm{ng} / \mathrm{ml}$ & $22(3.4)$ & $3(6.4)$ & & $1.60(0.45,5.63)$ \\
\hline
\end{tabular}

Totals may not equal $\mathrm{n}=703$ or $\mathrm{n}=369$ due to missing values.

abased on information gathered during clinical exam phase $(n=369)$.

associated with a seven-fold increased risk of prostatitis [6] Consistent with these findings, we observed that men reporting a history of prostatitis were approximately 11 times more likely to have had a previous diagnosis of BPH after adjustment for age. However, it is plausible that this association may be due to misdiagnosis as there is often significant overlap between $\mathrm{BPH}$ and prostatitis symptoms. Nickel [20] found that 5-20\% of men diagnosed with BPH have prostatitis-like symptoms, with over a third of men with previous diagnoses of $\mathrm{BPH}$ also having prostatitis in the past. Furthermore, it has been demonstrated that men with $\mathrm{BPH}$ have increased risk for urinary tract infections further supporting the notion that inflammation promotes recurrent infections, thus, perhaps, mediating prostatitis risk [21]. While we found that AUASI scores were higher among men with prostatitis, we found no difference in prostate volume when comparing men by history of prostatitis. In addition to these findings further highlighting the need for more stringent diagnostic criteria, they suggest that additional studies are necessary to elucidate whether a biologic relationship between the two conditions exists.

LUTS have been demonstrated consistently to be associated with prostatic inflammation, with $19 \%$ of men reporting urinary symptoms as the primary motivation to seek care for prostatitis [6]. In a study which evaluated the overlap of LUTS and pain, $57 \%$ of men with moderate/severe LUTS also reported pain symptoms [22]. Furthermore, men with young-onset prosta- titis were found to be 1.5 times more likely to develop LUTS compared to men without prostatitis [23]. Our study findings confirm these findings, as report of moderate/severe LUTS was significantly associated with a greater than two-fold increase in odds of prostatitis after adjustment for age.

Previous studies have documented conflicting evidence regarding the association between prostatitis and sexual frequency. The risk of prostatitis has been found to be lower in divorced and single men when compared to married men independent of age, suggesting a role of sexual frequency influenced by a man's exposure to pathogens in their wives genital tracts [9]. However, Collins et al. [5] found that men who ejaculate more frequently on a monthly basis have a greater odds of reporting a history of prostatitis. While no increase in risk according to marital status was observed in our study, we did observe a crude inverse relationship between prostatitis risk and sexual frequency. It is arguable that frequent sexual activity prevents the congestion of the prostatic ducts which increases the risk of prostatic infection. However, it is also plausible that the decrease in sexual frequency is the result of painful ejaculation associated with prostatitis.

An association between prostatitis and STDs has also been suggested. Collins et al. [5] reported an increased risk of prostatitis associated with history of sexually transmitted infections. Other literature further supports these findings suggesting that bacterial prostatitis may be the result of ascending urethral and urinary 
infections [8]. Furthermore, previous literature illustrates a relationship between STDs, prostatitis and prostate cancer risk, suggesting the interplay of these three conditions in an inflammatory/infectious pathway of carcinogenesis [12]. Our results do not support a significant association between prostatitis risk and a history of gonorrhea, syphilis or herpes. Also, no significant association was observed between partners history of cervical cancer and risk of prostatitis among the men in this study. The small percentage of study subjects reporting having STDs limits the ability to make inferences about true associations between STDs and prostatitis in our cohort.

Findings from our study also suggest that varying measures of stress are inversely related with prostatitis. Men with fair to poor emotional and physical health scores were more likely to have a history of prostatitis compared to men who rated their physical and emotional health to be good or excellent. Further supporting the idea that stress influences prostatitis risk, men with a higher number of stressful life events, lower social support scores and higher perceived stress were more likely to report prostatitis. Our findings are consistent with those of the Health Professionals Follow-up study which observed that men who reported stress at home or work had a 1.2-1.5 increased risk of prostatitis [5]. While it is well characterized that stress promotes infection ubiquitously, it is difficult to rule out reverse causation when characterizing stress as a risk factor for prostatitis, as stress could result in response to diagnosis [21].

In our study, BMI was found to have a protective effect on prostatitis risk after adjustment for age. Obese men (BMI > 30) were at a $68 \%$ decreased odds of having a history of prostatitis when compared to men with a $\mathrm{BMI}$ of $\leq 25$. Although similar findings were reported by Collins et al. [5], it is likely these findings are due to the influence of physical activity on this relationship. In this study, men who were vigorously physically active were at a $67 \%$ decreased odds of prostatitis after adjustment for age. Interestingly, a larger percentage (57.8\%) of the men characterized as obese in our sample were found to engage in vigorous exercise compared to overweight (4.8\%) and normal weight men (22.4\%). As physical activity is likely mediating the relationship between BMI and prostatitis in this cohort, we are unable to determine the direct effect of obesity on prostatitis independent of physical activity which has recently been found to be an effective treatment for men with prostatitis who are not responsive to other therapies. It is hypothesized that physical activity influences prostatic infection and resulting symptoms through improvements in pain sensitivity and changes in immune and autonomic functioning [24].
While the current study is one of the largest population-based studies of prostatitis in AfricanAmerican men, there are several limitations to consider. The primary limitation of this study is the susceptibility to recall bias as retrospective collection of exposures and outcome were based on self-reported physiciandiagnosis rather than serological or diagnostic confirmation. The definition of prostatitis includes a very heterogeneous group of diagnoses (NIH types I-IV). Our inability to distinguish between these types limits our ability to comprehensively study the predictors of prostatitis, as risk factors may differ by clinical manifestation. Additionally, because of the social stigma that surrounds STDs and sexual behavior, it is possible that participants under-reported exposures. However, it is unlikely this underreporting differed by prostatitis status and most likely resulted in an underestimation of the associations observed.

Secondly, due to the symptomatic overlap between $\mathrm{BPH}$ and prostatitis, it is possible that men with symptoms indicative of either prostatitis or $\mathrm{BPH}$ could have been misdiagnosed. Men who sought treatment for BPH may be more likely to have been diagnosed with prostatitis and vice versa. However, we found no significant associations between report of DRE or PSA testing during the last 5 years and history of prostatitis and when adjusted for these variables, the association between $\mathrm{BPH}$ and prostatitis increased suggesting a relationship independent of diagnostic testing. Finally, the cross-sectional nature of the data does not permit causal inferences to be made as factors such as stress and sexual behaviors could have occurred as a result of having prostatitis. Despite these limitations, the current study is one of the few to comprehensively investigate the relationships between lifestyle factors, sexual history, indicators of stress, measures of $\mathrm{BPH}$ and prostatic infection in African-American men.

In summary, our findings suggest that prostatitis is comparably prevalent in African-American and Caucasian men described in previously published reports. After adjustment for age, LUTS and history of BPH were associated with increased odds of prostatitis while increased BMI, physical activity and sexual frequency were found to decrease odds of prostatitis. Finally, poor emotional and physical health, high perceived stress and low social support were associated with an increased risk of prostatitis. Importantly, these findings suggest that the primary risk factors for this condition are largely modifiable and highlight potential targets for future prevention. Additional prospective research is needed to further characterize the etiology of prostatitis and elucidate the role of inflammation and infection in the natural history of prostatic disease in African-American men. 


\section{APPENDIX: PSYCHOSOCIAL STRESS MEASURES INDIVIDUALITEMS}

Perceived stress scale ${ }^{\mathrm{a}, \mathrm{b}}$

In the last 30 days, about how often did you feel...

(1) "that difficulties were piling up so high that you could not overcome them?"c

(3) "confident about your ability to handle personal problems?"

(4) "that things were going your way?"

Social Support ${ }^{\mathrm{d}, \mathrm{e}}$

"How much do your family members make you feel loved and cared for?"

"How much do your friends make you feel loved and cared for?"

"How much do you feel your family members make too many demands on you?"c

"How much do you feel your friends make too many demands on you?"25c

Stressful life events

(1) serious illness or injury that started or got worse

(2) being the victim of serious injury or assault

(3) retirement

(4) being laid off from work

(5) major financial difficulty

(6) death of someone close

(7) divorce or separation

Physical health $^{\mathrm{f}}$

"Would you say your health is excellent, very good, good, fair or poor?"

Emotional health ${ }^{\mathrm{f}}$

"What about your emotional health - how good you feel or how stressed, anxious or depressed you feel?"26

a5-point scale varying from 0 (very often) to 4 (never).

${ }^{\mathrm{b}}$ Individual scores were then summed to yield a summary score which ranged from 0 to 16 and dichotomized as $\geq 5$ (high stress) versus $<5$ (low stress) based on the median value for the sample. ${ }^{c}$ Negatively worded items were reverse-scored before analyzing. ${ }^{\mathrm{d}}$ Responses were measured on a 5 -point scaled from 0 (a great deal) to 4 (not at all).

${ }^{\mathrm{e}}$ Individual questions were dichotomized as $\geq 3$ (low support) versus $<3$ (high support).

f5-point scale varying from 0 (excellent) to 4 (poor).

\section{REFERENCES}

1. Pontari MA, Joyce GF, Wise M, McNaughton-Collins M. Prostatitis J Urol 2007; 177:2050.

2. Krieger JN, Nyberg L, Jr, Nickel JC. NIH consensus definition and classification of prostatitis. JAMA 1999;282:236.

3. Collins MM, Stafford RS, O'Leary MP, Barry MJ. How common is prostatitis? A national survey of physician visits. J Urol 1998; 159:1224.

4. Krieger JN, Riley DE, Cheah PY, Liong ML, Yuen KH. Epidemiology of prostatitis: New evidence for a world-wide problem [Review] [17 refs]. World J Urol 2003;21(2):70-7074.
5. Collins MM, Meigs JB, Barry MJ, Walker CE, Giovannucci E, Kawachi I. Prevalence and correlates of prostatitis in the health professionals follow-up study cohort. J Urol 2002;167(3): 1363-1366.

6. McNaughton Collins M, Stafford RS, Leary MP, Barry MJ. Distinguishing chronic prostatitis and benign prostatic hyperplasia symptoms: Results of a national survey of physician visits. Urology 1999;53:921.

7. Cheah PY, Liong ML, Yuen KH, Teh CL, Khor T, Yang JR, Yap HW, Krieger JN. Chronic prostatitis: Symptom survey with follow-up clinical evaluation. Urology 2003; 61:60.

8. Rothman I, Stanford JL, Kuniyuki A, Berger RE. Self-report of prostatitis and its risk factors in a random sample of middle-aged men. Urology 2004;64(5):876-879; discussion 879-80.

9. Mehik A, Hellstrom P, Lukkarinen O, Sarpola A, Jarvelin MR. Epidemiology of prostatitis in Finnish men: A population-based cross-sectional study. BJU Int 2000;86:443.

10. $\mathrm{Ku} \mathrm{JH}, \mathrm{Kim} \mathrm{ME}$, Lee NK, Park YH. Influence of environmental factors on chronic prostatitis-like symptoms in young men: Results of a community-based survey. Urology 2001;58:853.

11. Sutcliffe S, Giovannucci E, De Marzo AM, Leitzmann MF, Willett WC, Platz EA. Gonorrhea, syphilis, clinical prostatitis, and the risk of prostate cancer. Cancer Epidemiol Biomarkers Prev 2006; 15:2160

12. Sarma AV, McLaughlin JC, Wallner LP, Dunn RL, Cooney KA, Schottenfeld D, Montie JE, Wei JT. Sexual behavior, sexually transmitted diseases and prostatitis: The risk of prostate cancer in black men. J Urol 2006;176:1108.

13. Roberts RO, Bergstralh EJ, Bass SE, Lieber MM, Jacobsen SJ. Prostatitis as a risk factor for prostate cancer. Epidemiology 2004;15:93.

14. Beebe-Dimmer JL, Dunn RL, Sarma AV, Montie JE, Cooney KA. Features of the metabolic syndrome and prostate cancer in African-American men. Cancer 2007;109:875.

15. Cohen S, Kamarck T, Mermelstein R. A global measure of perceived stress. J Health Soc Behav 1983;24:385.

16. Dohrenwend BP. Inventorying stressful life events as risk factors for psychopathology: Toward resolution of the problem of intracategory variability. Psychol Bull 2006;132:477.

17. Golden-Kreutz DM, Andersen BL. Depressive symptoms after breast cancer surgery: Relationships with global, cancer-related, and life event stress. Psychooncology 2004;13:211.

18. Clemens JQ, Meenan RT, OKeeffe Rosetti MC, Kimes T, Calhoun EA. Prevalence of and risk factors for prostatitis: Population based assessment using physician assigned diagnoses. J Urol 2007;178: 1333.

19. Roberts RO, Bergstralh EJ, Bass SE, Leiber MM, Jacobsen SJ. Prostatitis as a risk factor for prostate cancer. Epidemiology 2004;15:93.

20. Nickel JC. The overlapping lower urinary tract symptoms of benign prostatic hyperplasia and prostatitis. Curr Opin Urol 2006; $16: 5$.

21. $\mathrm{Ku} \mathrm{JH}, \mathrm{Kim}$ SW, Paick JS. Epidemiologic risk factors for chronic prostatitis [Review] [37 refs]. Int J Androl 2005;28(6): 317-327.

22. Clemens JQ, Markossian TW, Meenan RT, O'Keeffe Rosetti MC, Calhoun EA. Overlap of voiding symptoms, storage symptoms and pain in men and women. J Urol 2007;178:1354.

23. Sutcliffe S, Giovannucci E, De Marzo AM, Willet WC, Platz EA. Sexually transmitted infections, prostatitis, ejaculation frequency, and the odds of lower urinary tract symptoms. Am J Epidemiol 2005;162(9): 898-8906. 
24. Giubilei G, Mondaini N, Minervini A, Saieva C, Lapini A, Serni S, Bartoletti R, Carini M. Physical activity of men with chronic prostatitis/chronic pelvic pain syndrome not satisfied with conventional treatments - Could it represent a valid option? The physical activity and male pelvic pain trial: A double-blind, randomized study. J Urol 2007;177:159.
25. Schuster TL, Kessler RC, Aseltine RH Jr. Supportive interactions, negative interactions, and depressed mood. Am J Community Psychol 1990;18:423.

26. Choi NG. Determinants of self-perceived changes in health status among pre- and early-retirement populations. Int J Aging Hum Dev 2003;56:197. 